Research Article

\title{
Reasonable Scope of Kilometer Drilling in Lower Layer of Extrathick Coal Seam: A Case Study of Tingnan Coal Mine, China
}

\author{
Delong Zou ${ }^{1}$ and Xiang Zhang $\mathbb{D}^{2}$ \\ ${ }^{1}$ Shenyang Research Institute of CCTEG, Shenyang 113122, China \\ ${ }^{2}$ State Key Laboratory of Coal Resources and Safe Mining, Beijing 100083, China \\ Correspondence should be addressed to Xiang Zhang; sqt1910101048@student.cumtb.edu.cn
}

Received 18 May 2021; Revised 14 June 2021; Accepted 26 June 2021; Published 13 July 2021

Academic Editor: Zou Quanle

Copyright (c) 2021 Delong Zou and Xiang Zhang. This is an open access article distributed under the Creative Commons Attribution License, which permits unrestricted use, distribution, and reproduction in any medium, provided the original work is properly cited.

\begin{abstract}
When stratified mining is adopted in high-gas and extrathick coal seam, a large amount of pressure-relief gas of the lower layer flows into the upper layer goaf along the cracks in the layer, resulting in upper layer working face to frequently exceed the gas limit. And ordinary drilling can no longer meet the requirements of the pressure-relief gas drainage of the lower layer. The 205 working face of Tingnan Coal Mine is taken as the test background in this paper, and based on the "pressure-relief and flow-increase" effect of the lower layer under the action of mining stress during the upper layer mining, the gas drainage of kilometer directional drilling in lower layer is studied. According to the distribution characteristics of support pressure before and after the working face, the pressure-relief principle, fracture development characteristics, and gas migration law of the lower layered coal body are analyzed in the process of advancing the upper layered working face in the extrathick coal seam with high gas. The maximum depth of goaf damage is calculated theoretically, and the Flac ${ }^{3 \mathrm{D}}$ numerical simulation of the failure deformation of the 205 working face floor is carried out. It is found that the maximum depth of plastic failure of the lower layer is about $13 \mathrm{~m}$. According to the plastic deformation of the lower layer under different vertical depths and the movement of coal and rock mass, it is determined that the reasonable range of kilometer directional drilling in the lower layer is 6-9 $\mathrm{m}$ below the floor vertical depth. From $15 \mathrm{~m}$ to $45 \mathrm{~m}$ in the two parallel grooves, there is no fracture failure with a sharp increase or decrease in the displacement in the local range. Meanwhile, in this part, the roof falling behind is not easy to compaction, and the displacement of the floor is large, which does not cause plastic damage. The degree of pressure relief is more sufficient, and the permeability of the lower layer is good. Therefore, drilling should be arranged as much as possible along the working face in this tendency range. The determination of reasonable arrangement range of kilometer directional drilling in extrathick coal seam provides reference index and theoretical guidance for industrial test of working face and also provides new ideas for gas control of stratified mining face in high-gas and extrathick coal seam.
\end{abstract}

\section{Introduction}

Coal resources will continue to dominate China's energy consumption for a long time in the future [1-5], and gas disasters in the process of coal resource development pose a great threat to safety in production [6-10]. Among them, when stratified mining is adopted in high-gas and extrathick coal seam, the pressure-relief gas of the lower layer flows into the upper layer goaf in large quantities along the cracks passing through strata, resulting in frequent gas overrun in the upper layer working face. It leads to severe challenges in gas control during the mining of high-gas and extrathick coal seam. At present, the methods of gas control in working face of high-gas and extrathick coal seam in China mainly include high-level gas drainage roadway, gas emission tail roadway, high-level drilling, ground drilling, and upward mesh drilling in floor rock roadway [11-13]. However, none of these methods can achieve directional and long-term extraction of pressure-relief gas in the lower layer, and the economic cost is relatively high. The effect is not ideal, and it is difficult to eliminate the threat of pressure-relief gas from the lower layer to the working face. The common parallel gas 
drainage borehole has the disadvantages of long construction period, high cost, and low efficiency. When it is applied to the gas drainage of the ultralong working face of the ultrathick coal seam with high gas, the gas drainage area is limited and cannot meet the requirements of the gas control of the working face. The kilometer directional drilling has the advantages of long coal seam section, open branch holes, large gas extraction area, high extraction efficiency, and slow gas flow attenuation in boreholes. Therefore, determining the reasonable range of the kilometer directional drilling in the lower layer to achieve a wide range of pressure-relief gas drainage in the lower layer for a long time has guiding significance and practical value for gas control work in large mining height working face of superthick coal seam with high gas.

The study of stress distribution and fracture evolution law of stope floor has important guiding significance for determining the reasonable range of kilometer directional drilling in lower layer. Meng et al. [14] established an elastic mechanical model for calculating the stress at any point of the floor according to the distribution law of abutment pressure in front of the working face, and the failure criterion of the floor rock mass is given by combining the Mohr-Coulomb criterion. Wang et al. [15] applied the elastoplastic mechanics theory to analyze the influence of different pressure steps on the failure depth and width of the floor from the perspective of dynamic and static loads, used numerical simulation to study the evolution of stress field and plastic zone of the floor under different pressure steps, and then put forward the prevention and control technology of water inrush from the floor of hydraulic fracturing pressure-relief of the roof. Zhang [16] studied the mechanism of water inrush in deep mines through experiments, and the total stress-strain permeability of different lithology of deep coal seam floor is determined. Xie and Chang [17] revealed the stress distribution characteristics of surrounding rock and the law of strata movement under the condition of no support in the floor of deep roadway through field measurement and numerical simulation. Guo et al. [18] believe that the damage range of surrounding rock and its influence on water-resisting layer of floor drainage roadway under the influence of mining are the key to determine the thickness of water-resisting layer of floor. In summary, a large number of scholars have studied the floor failure theory mainly from the perspectives of water inrush prevention, support failure caused by working face pressure, and roadway maintenance. However, when the stope floor is a coal body, there are few studies on its failure degree crack development and gas emission law. Aiming at the extraction technology of pressure-relief gas, scholars have done a lot of research around the mining protective layer [19-21]. The basic principle is to use the pressure-relief effect of the protected layer in the process of protective layer mining to strengthen the extraction of pressure-relief gas. Therefore, the protected layer is changed from high-gas outburst dangerous coal seam to low gas without outburst dangerous coal seam, so as to realize the safe and efficient mining of coal and gas resources [22-24]. At present, the theory and extraction technology of pressure-relief gas are mostly focused on the mining of upper and lower protective layers. When stratified mining is used in thick coal seams, there is no more scientific and field industrial test study on pressure-relief extraction of lower stratified coal seams. Kilometer directional drilling gas drainage has been widely used in China. Lu and Xiong [25] introduced in detail the advantages and disadvantages of conventional drilling rigs and underground kilometer directional drilling rigs through field tests. Regional gas drainage test was carried out by using kilometer drilling rig in Sihe Mine, Shanxi Province, which solved the problem of gas overrun during coal roadway excavation [26]. Combined with the newly introduced German DDR1200 kilometer directional drilling rig, Fang et al. [27] proposed a new method of drilling kilometer directional drilling in the roof fissure zone of the working face to extract gas and constructed a kilometer directional drilling coal and gas comining system. Xia et al. [28] carried out the comprehensive measures of gas extraction, including the wear layer and in-seam kilometer directional feathery drilling combined with multibranch technique. However, there is still a lack of research on whether the kilometer directional drilling can continue to extract gas after the pressure is relieved in the lower layered coal body of the extrathick coal seam. Moreover, pressure-relief gas drainage of the lower layer also involves the flow-solid coupling problem, in which the rock strata are constantly deformed by stress and the gas flow environment is constantly changing. Therefore, the deformation of rock mining and the mechanism of gas flow need comprehensive study to help solve the flow-solid coupling problem in underground gas drainage, which is an important topic for the prevention of the gas disasters [29-31].

In view of this, in this paper, we analyze the pressurerelief mechanism and pressure-relief gas migration law of lower layered coal body. Meanwhile, a combination of theoretical analysis and calculations, numerical simulations, and field tests is used to determine the reasonable range of the kilometer directional drilling group in the lower layer. It can not only help us predrainage the lower layer coal before mining but also achieve the purpose of long-term and highconcentration drainage of pressure-relief gas after mining.

\section{Engineering Background}

Tingnan Coal Mine is located in central and western Shanxi Province, as shown in Figure 1. The 4\# coal seam is the only recoverable coal seam in Tingnan Coal Mine. The general buried depth is $+500 \sim 700 \mathrm{~m}$, the coal seam thickness is $1.00 \sim 23.24 \mathrm{~m}$, and the average thickness is $11.05 \mathrm{~m}$. It is basically a good environmentally friendly power fuel and gasification coal.

The 205 working face is the second large mining height working face in the second panel of Tingnan Coal Mine, with an average thickness of $19 \mathrm{~m}$. It belongs to extrathick coal seam with an average dip angle of $4^{\circ}$. The working face is mined by inclined longwall comprehensive mechanized backward mining method. The upper layer is mined by $6 \mathrm{~m}$, and the lower layer is retained by $13 \mathrm{~m}$. The roof is comprehensively managed by caving method. The average 


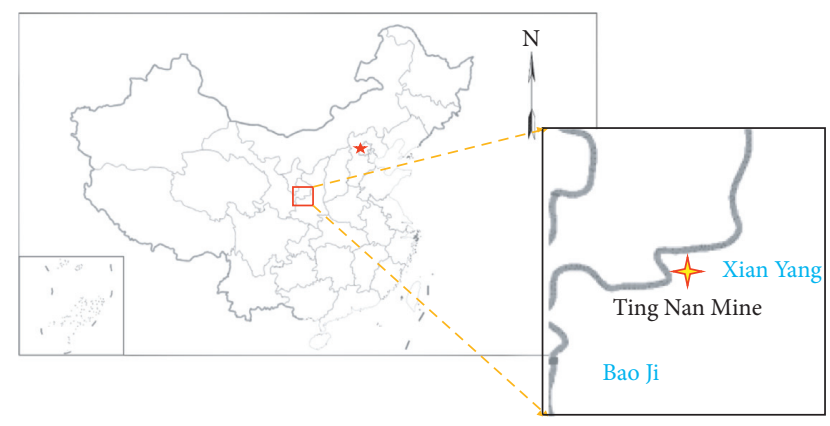

FIgUre 1: Location of Tingnan Coal Mine, Shanxi Province, China.

relative gas emission of 205 working face is $5.44 \mathrm{~m}^{3} \cdot \mathrm{t}^{-1}$, and the average absolute gas emission is $34.79 \mathrm{~m}^{3} \cdot \mathrm{min}^{-1}$. The recovery rate can reach more than $93 \%$ by using one-time full-height mining method, and the residual coal in goaf is less. The lower layer pressure-relief gas becomes the main source of goaf gas. Therefore, the lower layer has become the focus of gas control work. To sum up, predrainage of the coal seam and the lower layer must be carried out before the mining of the working face. At the same time, during the mining process and after the mining, the pressure-relief gas should be extracted by arranging reasonable drilling for a long time and high concentration.

According to the national standard, the gas basic parameters of $4 \#$ coal seam in 205 working face were measured in Tingnan Coal Mine. The measurement results are shown in Table 1.

\section{Analysis of Pressure-Relief Mechanism and Gas Migration Law of Lower Layer Coal}

3.1. Theoretical Analysis of Stratified Pressure-Relief under Mining Field. In the mining process of working face, the relationship between space and time of displacement of lower layer coal and rock mass is three stages: compression of stress concentration zone, expansion of pressure-relief zone, and compaction of recovery zone. About $15 \mathrm{~m}$ away from the working face, the in situ stress increases exponentially, and the in situ stress reaches the peak at about $8 \mathrm{~m}$. This area is the compression of stress concentration zone, and the support pressure coefficient $n$ varies from $n \geq 1.5$ to $5 \gamma \mathrm{H}$. The coal in this part of the region is gradually compacted under the action of higher than the original stress, and the coal seam and floor have a slow downward trend, resulting in compression displacement. In the rear of the working face, the ground stress is less than the original stress, and the concentrated support pressure in the front is transmitted to the bottom of the goaf through the floor coal and rock mass, resulting in floor heave deformation. As the working face continues to move forward the expansion displacement increases gradually, this area is the expansion of pressure-relief zone. When a certain distance is reached, the coal gangue falling from the goaf far away from the working face is gradually compacted, and the displacement of the floor is gradually restored, but it cannot recover to the initial value. This area is the compaction of recovery zone. The permeability of lower layer coal also experiences a process of decreasing, increasing, and decreasing again. This process repeats as the working face advances, and the floor is continuously damaged periodically.

In this process, the formation and development of the plastic zone are mainly caused by the floor heave of the upper layer floor in actual production. After the upper slicing mining, the surrounding area of goaf is the support pressure concentration area. When the stress of the coal and rock mass in the support pressure action area (area I in Figure 2: active area) exceeds its ultimate strength, the coal mass will produce plastic deformation. At the same time, this part of the coal and rock mass is squeezed in the vertical direction, and the coal mass will inevitably produce expansion deformation in the horizontal direction. The expanded coal and rock mass squeezes the coal and rock mass in the transition area (area II: transition area) and transfers the stress to this area. The coal and rock mass in area II continues to squeeze forward the coal and rock mass in the passive area (area III: passive zone). Because only area III is at the floor of the goaf, it has a relatively large free space and free surface, which causes the coal and rock mass in the transition area and the passive area to expand and uplift to the goaf under the action of the force transmitted by the active area.

In the critical area of expansion zone and compression zone of the lower layer, coal and rock mass are prone to shear failure. In the process of pressure relief, the coal and rock mass in the expansion area is prone to separate layer cracks, vertical cracks, and cross cracks, resulting in a hundred times increase in the permeability coefficient of coal seam. And the coal body in the goaf floor is fully released, which provides a prerequisite basis for efficient extraction of pressure-relief gas in lower layers [32-35].

\subsection{Destruction of Lower Stratified Space under Theoretical Calculation}

3.2.1. Plastic Solution of Maximum Failure Depth of Floor along Strike. According to the comprehensive calculation formula of ultimate bearing capacity of rock and soil, the ultimate load formula of floor rock mass is proposed.

$$
P_{0}=\left(C \cot \varphi_{0}+m \gamma H+\gamma x_{a} \tan \varphi_{0}\right) e^{\left(\pi \tan \varphi_{0}\right)} \tan ^{2}\left(\frac{\pi}{4}+\frac{\varphi_{0}}{2}\right)+\gamma x_{a} \tan \varphi_{0}-C \cot \varphi_{0},
$$


TABLE 1: Basic parameter test result of coal seam gas in 205 working face.

\begin{tabular}{|c|c|c|}
\hline Coal seam & & $4 \#$ \\
\hline Gas content $\left(\mathrm{m}^{3} \cdot \mathrm{t}^{-1}\right)$ & & $6.74 \sim 6.86$ \\
\hline & $a\left(\mathrm{~m}^{3} \cdot \mathrm{t}^{-1} \cdot \mathrm{r}^{-1}\right)$ & $21.578 \sim 22.321$ \\
\hline Gas adsorption constant & $b\left(\mathrm{MPa}^{-1}\right)$ & $0.879 \sim 0.926$ \\
\hline & Moisture (\%) & $4.78 \sim 5.46$ \\
\hline Industrial analysis & Ash (\%) & $7.43 \sim 7.88$ \\
\hline & Volatile (\%) & $29.45 \sim 32.65$ \\
\hline Gas pressure $(\mathrm{MPa})$ & \multicolumn{2}{|c|}{$0.54 \sim 0.624$} \\
\hline Coal porosity $\left(\mathrm{m}^{3} \cdot \mathrm{m}^{-3}\right)(\%)$ & \multicolumn{2}{|c|}{$8.48 \sim 8.86$} \\
\hline Initial velocity of gas emission $(\Delta p)$ & \multicolumn{2}{|c|}{0.775} \\
\hline Coal seam permeability coefficient $\left(\mathrm{m}^{2} \cdot \mathrm{MPa}^{-2} \cdot \mathrm{d}^{-1}\right)$ & \multicolumn{2}{|c|}{0.0424} \\
\hline Natural gas flow attenuation coefficient of borehole $\left(\mathrm{d}^{-1}\right)$ & \multicolumn{2}{|c|}{0.0243} \\
\hline Coal dust explosive & \multicolumn{2}{|c|}{ Risk of explosion } \\
\hline Coal seam spontaneous combustion tendency & \multicolumn{2}{|c|}{ Type II spontaneous combustion } \\
\hline
\end{tabular}

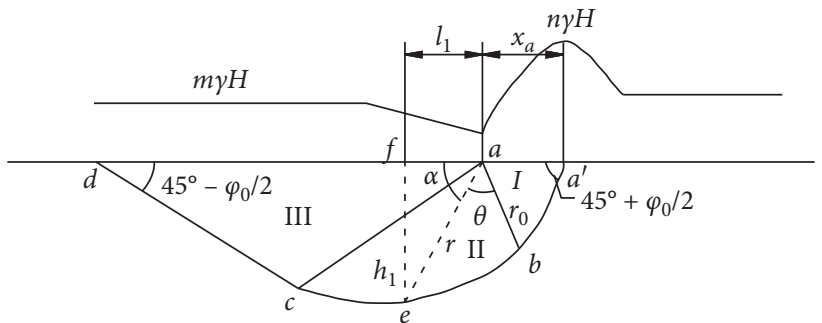

FIgURe 2: Calculation diagram of the most destroy depth in seam floor.

where $C$ is the cohesion of rock mass and $x_{a}$ is the length of yield zone of coal pillar. The plastic zone of the floor can be divided into three parts, namely, I: active zone, II: swelling rock mass squeezing transition zone, and III: rock mass in the transition zone, which continues to squeeze the passive zone. To determine the maximum depth and length of the failure zone under the condition of ultimate bearing pressure, it can be calculated according to the geometric dimensions of the limit plastic zone in Figure 2.

$$
\begin{aligned}
\text { In } \triangle \mathrm{aba}^{\prime}, \mathrm{ab} & =r_{0}=\frac{x_{a}}{2} \cos \left(\frac{\pi}{4}+\frac{\varphi}{2}\right), \\
\text { In } \Delta \mathrm{aef}, h & =r \sin \alpha, \\
\text { And } \alpha & =\frac{\pi}{2}-\left(\frac{\pi}{4}+\frac{\varphi_{0}}{2}\right)-\theta, \\
\text { And so, } h & =r_{0} e^{\left(\theta \tan \varphi_{0}\right)} \cos \left(\theta+\frac{\varphi_{0}}{2}-\frac{\pi}{4}\right) .
\end{aligned}
$$

From $\mathrm{d} h / \mathrm{d} \theta=0$, the maximum depth of the damage zone $h$ can be obtained.

$$
\begin{aligned}
\frac{\mathrm{d} h}{\mathrm{~d} \theta}= & r_{0} e^{\left(\theta \tan \varphi_{0}\right)} \cos \left(\theta+\frac{\varphi_{0}}{2}-\frac{\pi}{4}\right) \tan \varphi_{0} \\
& -r_{0} e^{\left(\theta \tan \varphi_{0}\right)} \sin \left(\theta+\frac{\varphi_{0}}{2}-\frac{\pi}{4}\right)=0 .
\end{aligned}
$$

$$
\begin{gathered}
\text { Hence, } \tan \varphi_{0}=\tan \left(\theta+\left(\left(\varphi_{0} / 2\right)-(\pi / 4)\right)\right) \\
\theta=\frac{\pi}{4}+\frac{\varphi_{0}}{2} .
\end{gathered}
$$

Substituting (4) and $r_{0}$ into (2), the maximum damage depth of the rock mass $h$ can be obtained.

$$
h=\frac{x_{a} \cos \varphi_{0}}{2 \cos \left((\pi / 4)+\left(\varphi_{0} / 2\right)\right)} e\left(\frac{\pi}{4}+\frac{\varphi_{0}}{2}\right) \tan \varphi_{0} .
$$

Therefore, the horizontal distance $l_{1}$ between the maximum failure depth of floor coal and rock mass and the working face end is

$$
l_{1}=h_{1} \tan \varphi_{0} .
$$

According to the field measurement of the mining face in the first and second panel of Tingnan Coal Mine, especially the length of the coal seam yield zone in the 204 working face, it shows that when the working face advances, the influence area of plastic zone width of coal seam is not the peak point, but a dynamic influence range. The distance between the peak abutment pressure of 204 comprehensive working face and the edge of coal body (equal to the width of plastic zone $x_{a}$ ) is $8 \sim 11 \mathrm{~m}$.

Using the empirical formula (7) of coal seam yield length ( $H$ is the average depth of coal seam in working face), the average buried depth of 205 working face is $580 \mathrm{~m}$, and the length of coal seam yield zone $x_{a}$ calculated is $8.7 \mathrm{~m}$, which is basically consistent with the field measurement. Therefore, 
this formula can be used as the calculation of yield zone length of 205 working face, and finally, $x_{a}$ is determined to be $3 \mathrm{~m}$.

$$
x_{a}=0.015 H .
$$

Substituting (7) into (5), we can obtain that

$$
h=\frac{8.7 \cos \varphi_{0}}{2 \cos \left((\pi / 4)+\left(\varphi_{0} / 2\right)\right)} e\left(\frac{\pi}{4}+\frac{\varphi_{0}}{2}\right) \tan \varphi_{0},
$$

where coal seam internal friction angle of 205 working face is $28^{\circ}$. The calculated $h$ is $12.89 \mathrm{~m}$ and $l_{1}$ is $6.85 \mathrm{~m}$. The calculation shows that the $13 \mathrm{~m}$ coal body in the lower layer is almost all in the pressure-relief fracture zone.

According to the calculation results, the distribution pattern of plastic failure zone in the lower layer of 205 working face of $4 \#$ coal seam in Tingnan Coal Mine is shown in Figure 3.

\subsubsection{Distribution Law of Failure Depth along Inclined Floor.} The problem analyzed in this paper is the plane strain state. The stress generated by the self-weight of the rock mass in the floor is equal to $\gamma z$. The stress analysis is shown in Figure 4; then, the principal stress of $M$ at any point in the floor strata is

$$
\begin{aligned}
\sigma_{1} & =\frac{q}{\pi}(\alpha+\sin \alpha)+\gamma z, \\
\sigma_{2} & =v\left(\sigma_{1}+\sigma_{3}\right) \\
& =\frac{2 q v a}{\pi}+2 \gamma z, \\
\sigma_{3} & =\frac{q}{\pi}(\alpha-\sin \alpha)+\gamma z .
\end{aligned}
$$

Under the action of multidirectional stress, the failure of rock mass obeys the Mohr-Coulomb failure criterion, that is, $\sigma_{1}-K \sigma_{3}=R_{c}$, and after substituting equations (9)-(11),

$$
z=\frac{q}{\pi \gamma}\left(\frac{K+1}{K-1} \sin \alpha-\alpha\right)-\frac{R_{c}}{\gamma(K-1)},
$$

where $R_{c}$ is the uniaxial compressive strength of rock mass and $\gamma$ is the volume weight of rock mass.

$$
\begin{aligned}
& K=\frac{1+\sin \varphi}{1-\sin \varphi}, \\
& \alpha=\cos ^{-1} \frac{K-1}{K+1} .
\end{aligned}
$$

According to formula (12), the division map of the failure zone of the floor rock mass can be drawn. As shown in Figure 5, the failure zone develops from inside to outside in the order of 1-2-3-4. It can be concluded that the failure depth of rock mass near the edge of working face is the largest. According to the distribution characteristics of failure depth under the ultimate state of floor shown in Figures 2 and 5, the distribution pattern of floor failure zone can be deduced. Figure 6(a) shows the distribution of the

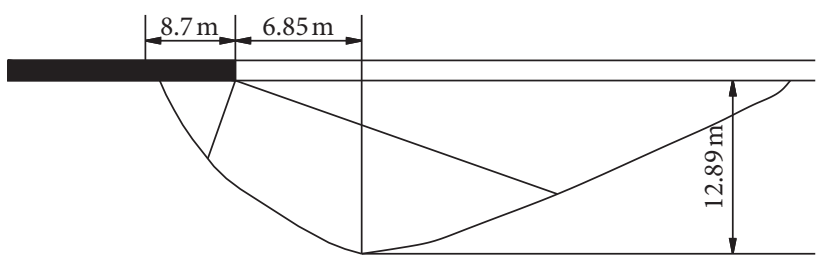

FIgURE 3: Figure of failing zone of 205 working face floor (it is theoretical result).

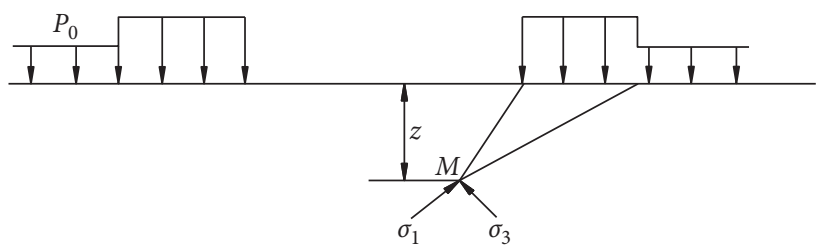

FIgURE 4: The sketch map of stress simplification of coal floor $\left(P_{0}\right.$ : primary stress).

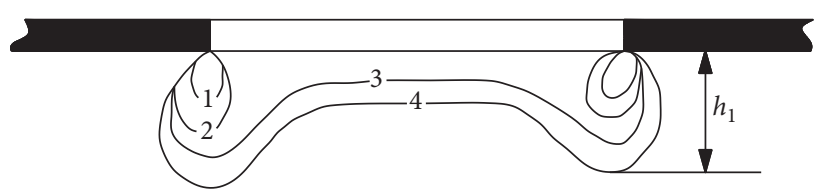

Figure 5: Developing process of rock failing zone.

failure zone along the inclined direction of the working face in the near-horizontal coal seam, and Figure 6(b) shows the distribution of the failure zone along the advancing direction (strike) of the working face.

For the near-horizontal coal seam mining, the depth distribution of the floor failure zone along the inclined direction is in the shape of an "inverted saddle," and the failure depth on both sides is often greater than that in the middle part of the goaf. Therefore, the influence of the failure depth on both sides should be paid attention to when arranging the boreholes.

3.3. Migration Law of Lower Layer Pressure-Relief Gas and Pressure-Relief Gas Extraction Technology. When the 205 working face is mined, the lower layer is affected by mining. The coal body of the goaf floor heaves to the free space of the goaf and moves, deforms, and even destroys. A large number of primary micropores develop into cracks with large diameters. In this process, the permeability coefficient of coal seam is increased by hundreds of times, and the process of gas "desorption-diffusion-seepage" is accelerated. A large number of bedding tension fractures through-layer fractures and cross fractures formed by the full development of coal fractures provide a network channel for the flow and collection of pressure-relief gas in the lower layer, so the mining of the upper layer will have the effect of "pressure relief and flow increase" on the lower layer [36], as show in Figure 7.

The pressure-relief gas gathers along the bedding in the coal seam, and the gas flows from the high-pressure area to the low-pressure area, which cannot diffuse out of the coal seam. Then, the pressure-relief gas in the area must be 


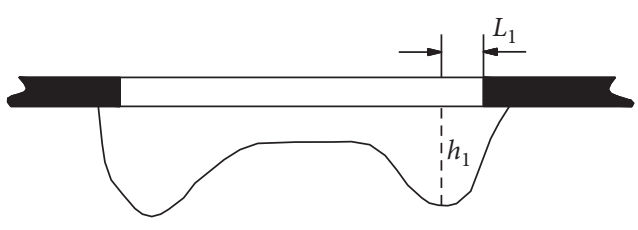

(a)

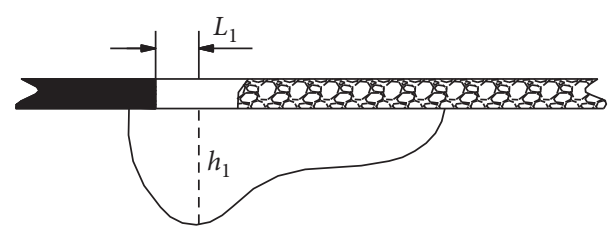

(b)

Figure 6: Distribution for $m$ of coal floor failing zone in flat seam.

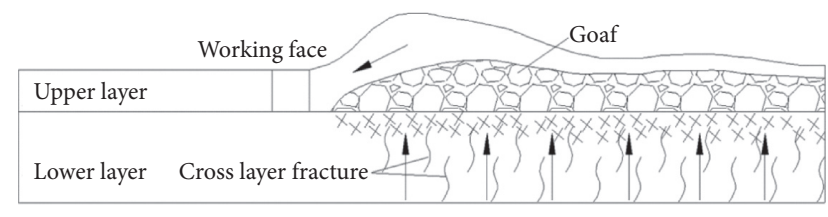

Figure 7: Pressure-relief gas flow in lower slice.

extracted under the negative pressure of the extraction borehole. With the increase of the vertical depth, the coal is still in the plastic deformation stage. Therefore, the shear stress and tensile stress gradually decay. The failure ability of the coal is also weakening, and the coal itself is not destroyed in the state of crisp. When the kilometer directional drilling is located in the area where the plastic deformation of the coal body is less than the limit deformation, the drilling will not be damaged or the degree of damage is relatively small, which can achieve better self-stability and maintain the integrity of the drilling, and the fracture can be significantly expanded. In the actual production operation, the kilometer directional drilling is fast in construction and low in cost, which can effectively extract gas. And the biggest advantage of kilometer directional drilling is that it not only can be preextracted before mining, mining while pumping, but also can be continuous pumping after mining. The above provides a strong basis for the selection of downward kilometer directional drilling drainage technology.

\section{Numerical Simulation of Floor Failure Deformation of 205 Working Face}

4.1. Modelling and Parameter Selection. Figure 8 shows the model established using FLAC ${ }^{3 \mathrm{D}}$. Model coordinate system parameters are $x$ (working face dip direction) $=300 \mathrm{~m}, y$ (working face mining direction) $=300 \mathrm{~m}$, and $z$ (vertical to coal strata upward $)=160 \mathrm{~m}$. The average dip angle of $4 \#$ coal seam in the second panel is $4^{\circ}$, which belongs to the nearhorizontal coal seam. When establishing the model, the dip angle of coal seam is simplified to $0^{\circ}$. The thickness of the upper layer was $6 \mathrm{~m}$, and that of the lower layer was $13 \mathrm{~m}$. The length of the working face was $200 \mathrm{~m}$. Per step is $20 \mathrm{~m}$, and a total of 10 steps is excavated. Considering the need to focus on the deformation and stress distribution of the direct bottom and the lower layer, the deformation of the overlying strata is not taken into account. The mining layer, the direct bottom, and the lower layer in the model are refined, and the movement monitoring of the upper layer floor is carried out for every $1 \mathrm{~m}$. The whole model uses brick initial grid. There are 187200 areas and 197213 nodes after grid division.
The uniform vertical downward stress load is applied in the top boundary of the model $(z=160 \mathrm{~m})$ so that it is equal to the weight of the overlying strata $P . P$ is equal to the product of the burial depth of the upper surface strata in the model and the average bulk density of the overlying strata. From the surface to the upper surface of the model, the burial depth is about $450 \mathrm{~m}$, and the loess layer is about $170 \mathrm{~m}$. Therefore, the vertical downward uniform stress load $P$ is $8.3 \mathrm{MPa}$. At the same time, the fixed hinge support is set at the floor. Horizontal displacement constraints are applied at $x=0 \mathrm{~m}, x=300 \mathrm{~m}, y=0 \mathrm{~m}$, and $y=300 \mathrm{~m}$. According to the geological characteristics and mining technical conditions of Tingnan Coal Mine, the Mohr-Coulomb plastic constitutive model and Mohr-Coulomb failure criterion are selected in this simulation, and the large strain deformation mode is adopted in the strain mode. The use of mechanical parameters of coal and rock not only refers to the test data of the laboratory but also combines with the actual investigation. The bulk modulus is obtained according to the empirical value, and the mechanical parameters of rock mass are shown in Table 2.

\subsection{Analysis of Numerical Simulation Results}

4.2.1. Vertical Stress Distribution Law of Floor during Mining. In the model, the original rock stress is in the original equilibrium state before the 4\# coal layer is pushed and mined. After 13978 steps of initial equilibrium, the vertical stress distribution of coal seam is relatively balanced and has a good horizon. The original vertical stress of each coal seam in the model is $8.5 \sim 12.28 \mathrm{MPa}$. The stress of each stratum is similar to the calculated self-weight stress of the overlying rock mass, as shown in Figure 9. After the 10-step push is completed, the total iteration of the model balance is 83367 steps.

With the advance of the upper layer of $4 \#$ coal in the model, the original rock stress is redistributed, and the stress concentration area and pressure-relief area appear. In order to better reflect the change of stress distribution in the process of working face advancing, representative vertical stress change distribution maps are selected. In the middle line of the working face along, the strike was selected to advance to $20 \mathrm{~m}, 60 \mathrm{~m}, 100 \mathrm{~m}, 140 \mathrm{~m}, 180 \mathrm{~m}$, and $200 \mathrm{~m}$ sections; see Figure 10.

It can be seen from Figure 10 that the dark blue area at the working face and the cutting hole is the stress concentration area. The maximum stress is $21 \sim 23 \mathrm{MPa}$ at $200 \mathrm{~m}$, and the stress concentration coefficient is about 2.3, which is 


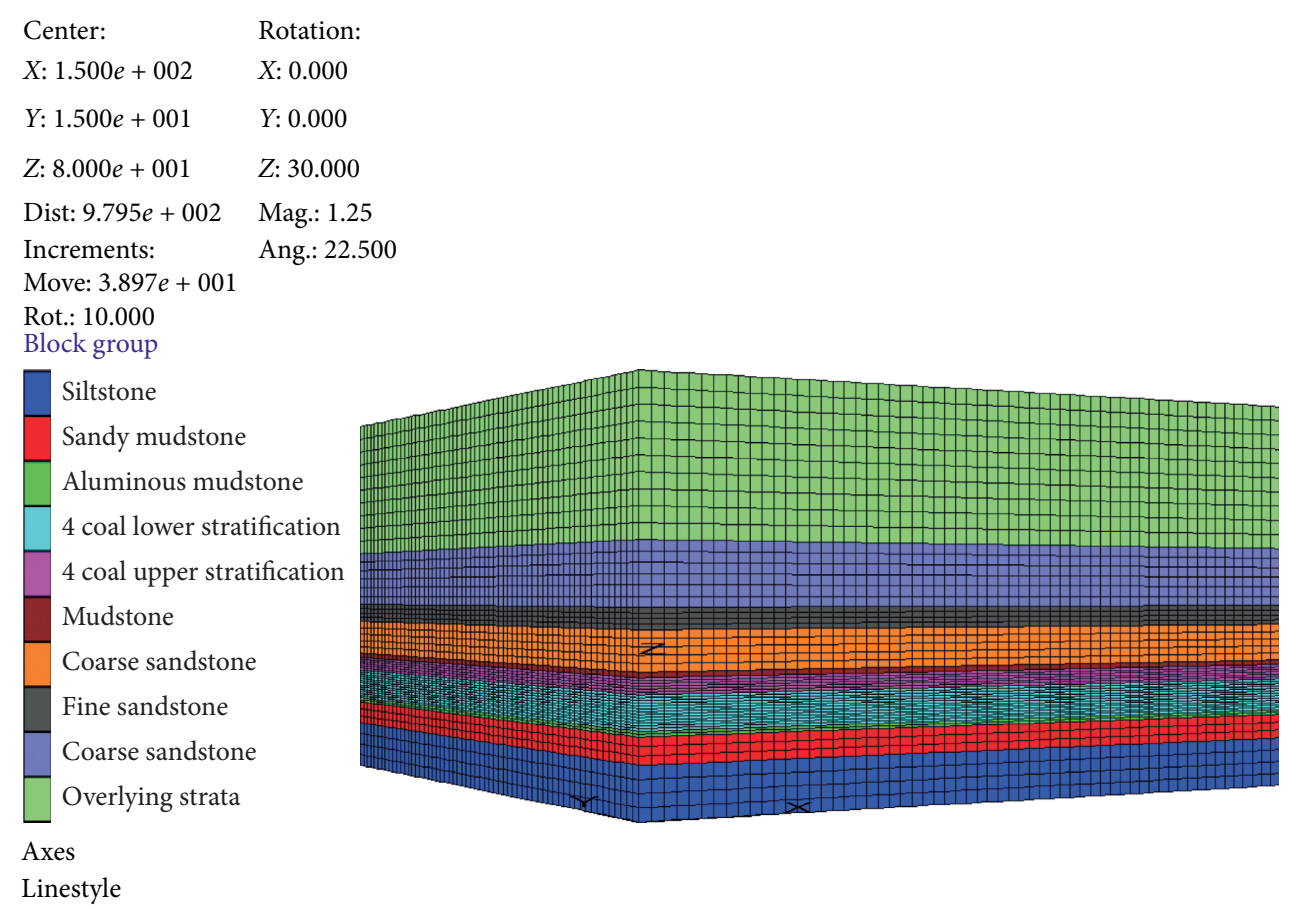

FIgURE 8: Three-dimensional numerical model.

TABle 2: Physicomechanical parameters of coal and rock layers.

\begin{tabular}{|c|c|c|c|c|c|c|c|}
\hline Lithology & $\begin{array}{c}\text { Thickness } \\
(\mathrm{m})\end{array}$ & $\begin{array}{l}\text { Bulk modulus } \\
(\mathrm{GPa})\end{array}$ & $\begin{array}{c}\text { Shear modulus } \\
(\mathrm{GPa})\end{array}$ & $\begin{array}{c}\text { Density } \\
\left(\mathrm{kg} \cdot \mathrm{m}^{-3}\right)\end{array}$ & $\begin{array}{c}\text { Cohesion } \\
(\mathrm{MPa})\end{array}$ & $\begin{array}{c}\text { Internal friction } \\
\text { angle }\left({ }^{\circ}\right)\end{array}$ & $\begin{array}{c}\text { Tensile strength } \\
(\mathrm{MPa})\end{array}$ \\
\hline Overlying strata 10 & 60 & 4.60 & 4.45 & 2500 & 3.50 & 38 & 1.35 \\
\hline Grit stone 9 & 24 & 4.53 & 4.37 & 2510 & 2.53 & 34 & 1.26 \\
\hline $\begin{array}{l}\text { Fine-grained } \\
\text { sandstone } 8\end{array}$ & 8 & 4.64 & 4.32 & 2540 & 4.57 & 35 & 1.35 \\
\hline Grit stone 7 & 15 & 4.58 & 4.42 & 2530 & 2.57 & 34 & 1.28 \\
\hline Mudstone 6 & 2 & 4.54 & 4.31 & 2560 & 2.08 & 32 & 1.32 \\
\hline $\begin{array}{l}\text { Upper layer of } 4 \# \\
\text { coal seam } 5\end{array}$ & 6 & 1.42 & 0.57 & 1400 & 1.2 & 28 & 0.64 \\
\hline $\begin{array}{l}\text { Lower layer of } 4 \# \text { coal } \\
\text { seam } 4\end{array}$ & 13 & 1.42 & 0.57 & 1400 & 1.2 & 28 & 0.64 \\
\hline $\begin{array}{l}\text { Aluminum } \\
\text { mudstone } 3\end{array}$ & 2 & 4.87 & 4.79 & 2420 & 1.76 & 39 & 1.31 \\
\hline Sandy mudstone 2 & 10 & 4.52 & 4.34 & 2560 & 2.08 & 36 & 1.35 \\
\hline Siltstone 1 & 20 & 4.67 & 4.53 & 2550 & 4.58 & 39 & 1.42 \\
\hline
\end{tabular}

about $7.5 \mathrm{~m}$ in front of the working face. At the top and bottom of the working face, orange or red area is called lower than the original rock stress area, which belongs to the pressure-relief area. The pressure relief of the red area of coal and rock is the most sufficient.

With the continuous advancement of the working face, the range of the pressure-relief area is increasing, and the pressure-relief range of the floor is far smaller than that of the roof. When advancing to $160 \mathrm{~m}$, the pressure-relief depth is basically at a stable value and does not become deeper or increase slightly with the advance of the working face. On the whole, the vertical stress of the floor near the cutting hole is restored with the advancement of the working face, and the pressure-relief degree of the floor is attenuated from the inside to the outside. The greater the vertical depth from the floor, the smaller the pressure relief and deformation of the coal body. The pressure-relief range is always semielliptic, and the pressure-relief area is basically symmetrically distributed. The pressure-relief range of the roof is much larger than that of the floor. The pressure relief in the middle of the roof is the largest, and the caving is more sufficient than the two sides. It can be seen that compared to the roof, pressurerelief range of floor is limited, and the degree of coal damage is small. It provides the possibility for the complete existence 


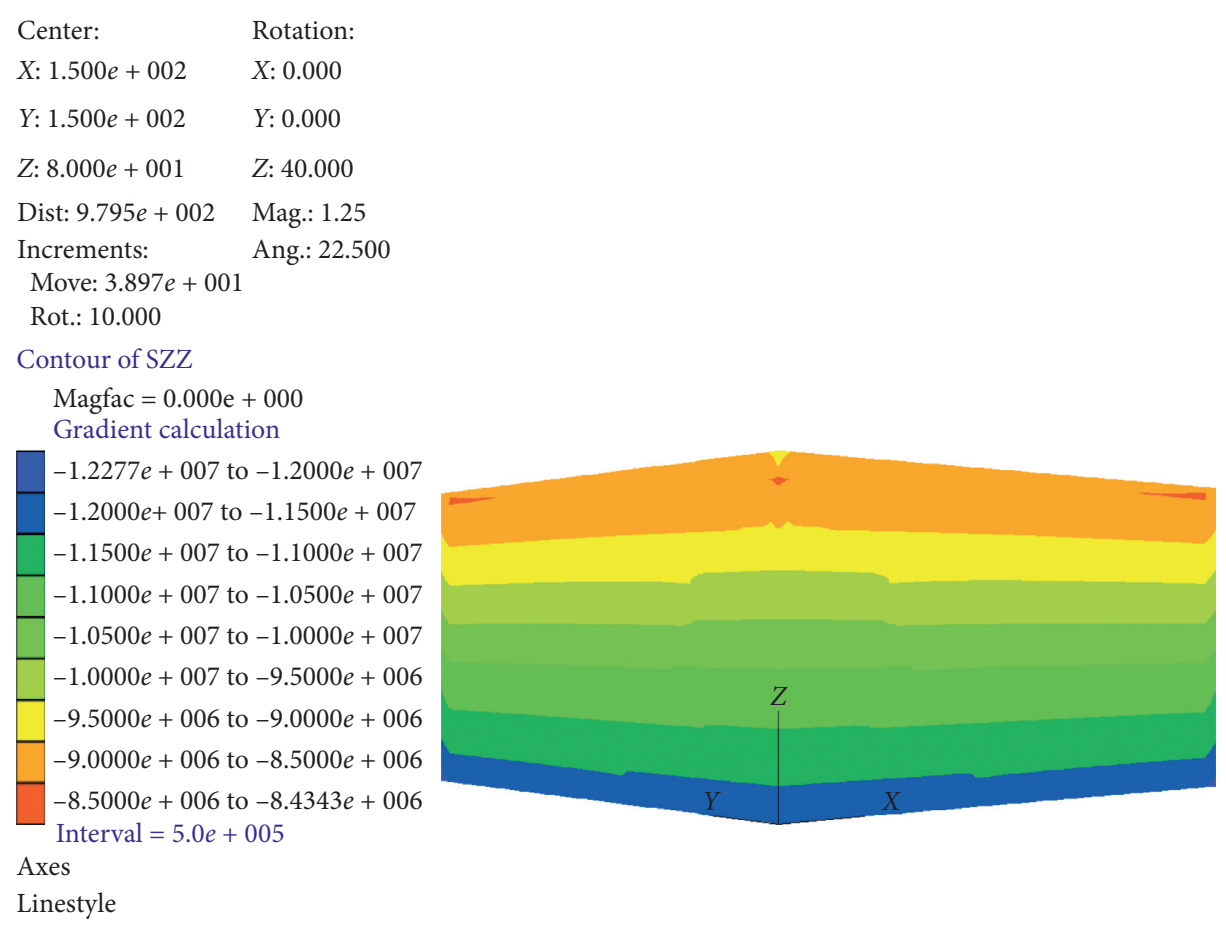

FIGURE 9: Distribution of vertical stress after premining initial balance.

of kilometer borehole in the lower layer and the completion of gas drainage.

4.2.2. Variation Law of Plastic State of Floor during Mining. The maximum plastic failure depth of the floor of the working face rises rapidly at the beginning stage. When the working face is advanced to $160 \mathrm{~m}$, the failure tends to be stable and does not expand to the deep with the advance of the working face. When the working face is advanced to $200 \mathrm{~m}$, the maximum failure depth is $14.5 \mathrm{~m}$, as shown in Figure 11.

Therefore, the plastic change of the floor under different vertical depths when the working face advances to $200 \mathrm{~m}$ is analyzed, and the plastic change maps of $1 \mathrm{~m}, 3 \mathrm{~m}, 6 \mathrm{~m}, 9 \mathrm{~m}$, $12 \mathrm{~m}$, and $14 \mathrm{~m}$ under the vertical depth of the floor are derived, respectively. As shown in Figure 12, the arrow in the figure indicates the direction of the working face.

It can be seen from Figure 12 that, under the floor of $1 \mathrm{~m}$ and $3 \mathrm{~m}$, the goaf is plane shear and tensile failure, and the surrounding is mainly shear failure. The coal body was severely damaged, causing dislocation and movement, and the penetration cracks were fully developed. At $6 \mathrm{~m}$ below the floor, the "O" shear failure is the main type around the mined-out area, and the tensile failure is the main type in the middle part with a little shear failure. The coal body starts from severe damage to crack damage. At $9 \mathrm{~m}$ below the floor, shear failure occurs around the goaf, with a little shear failure in the middle part, and the plastic deformation is very small. The coal body is in a slight disturbance state, and the borehole will not produce substantive collapse in this layer. When it is $12 \mathrm{~m}$ below the floor, only continuous shear failure occurs around the goaf. Other areas are basically not affected by damage, and the coal disturbance is relatively small. When it is $14 \mathrm{~m}$ below the floor, only intermittent shear failure occurs around the goaf. Other areas are basically not affected by damage, and coal is basically not affected. The rock strata below $14 \mathrm{~m}$ are basically not destroyed.

In general, the maximum plastic failure depth of the floor in accordance with the third chapter is near the two parallel grooves. In the whole mining-induced fracture field of the lower layer, the plastic zone is relatively shallow in the middle of the goaf and deep around it, with the shape of "return" circle.

4.2.3. Variation Law of Displacement of Coal and Rock Mass in Floor during Mining. When the working face advances to $200 \mathrm{~m}$, the local displacement of the floor has reached the maximum. Therefore, starting from the coal wall of the working face, at $3 \mathrm{~m}, 5 \mathrm{~m}, 7 \mathrm{~m}$, and $9 \mathrm{~m}$ in the goaf along the strike direction, the section maps are made along the inclination of the working face, and the contour map of the vertical displacement of coal and rock mass is plotted, as shown in Figure 13.

It can be seen from the figure that when the working face is mined for $200 \mathrm{~m}$, the displacement at different depths of the floor is different. The more it goes to the goaf direction, the larger the displacement at the same vertical depth at the same position is. It can be seen from Figure 13 that when the coal wall of the working face is about $20 \mathrm{~m}$ away from the goaf, the floor displacement reaches the maximum value. The isoline with a vertical displacement of $0 \mathrm{~m}$ of the floor is approximately $24 \mathrm{~m}$ below the vertical depth. At the junction of the compression zone and the expansion zone of the 


\begin{tabular}{|c|c|}
\hline & Rotation: \\
\hline$X: 1.500 e+002$ & $X: 0.000$ \\
\hline$Y: 1.500 e+002$ & $Y: 0.000$ \\
\hline$Z: 8.000 e+001$ & $Z: 90.000$ \\
\hline Dist: $9.795 e+002$ & Mag.: 1.95 \\
\hline \multicolumn{2}{|c|}{$\begin{array}{l}\text { Increments: Ang.: } 22.50 \\
\text { Move: } 3.897 e+001 \\
\text { Rot.: } 10.000\end{array}$} \\
\hline Plane origin: & Plane normal: \\
\hline$X: 1.500 e+002$ & $X: 1.000 e+000$ \\
\hline$Y: 0.000 e+000$ & $Y: 0.000 e+000$ \\
\hline$Z: 0.000 e+000$ & $Z: 0.000 e+000$ \\
\hline \multicolumn{2}{|l|}{ Contour of SZZ } \\
\hline \multicolumn{2}{|c|}{ Plane: on } \\
\hline \multicolumn{2}{|c|}{ Magfac $=1.000 e+000$} \\
\hline \multicolumn{2}{|c|}{ Gradient calculation } \\
\hline \multicolumn{2}{|c|}{$-1.7403 e+007$ to $-1.6000 e+007$} \\
\hline \multicolumn{2}{|c|}{$-1.6000 e+007$ to $-1.4000 e+007$} \\
\hline \multicolumn{2}{|c|}{$-1.4000 e+007$ to $-1.2000 e+007$} \\
\hline \multicolumn{2}{|c|}{$-1.2000 e+007$ to $-1.0000 e+007$} \\
\hline \multicolumn{2}{|c|}{$-1.0000 e+007$ to $-8.0000 e+006$} \\
\hline \multicolumn{2}{|c|}{$-8.0000 e+006$ to $-6.0000 e+006$} \\
\hline \multicolumn{2}{|c|}{$-6.0000 e+006$ to $-4.0000 e+006$} \\
\hline \multicolumn{2}{|c|}{$-4.0000 e+006$ to $-2.0000 e+006$} \\
\hline \multicolumn{2}{|c|}{$-2.0000 e+006$ to $0.0000 e+000$} \\
\hline
\end{tabular}

Center:

Rotation:

$X: 1.500 e+002$

X: 0.000

$Y: 1.500 e+002$

$Y: 0.000$

$Z: 8.000 e+001$

Z: 90.000

Dist: $9.795 e+002$

Increments:

Mag.: 1.95

Move: $3.897 e+001$

Rot.: 10.000

Plane origin:

Plane normal:

$X: 1.500 e+002$

$X: 1.000 e+000$

$Y: 0.000 e+000$

$Y: 0.000 e+000$

Z: $0.000 e+000$

$Z: 0.000 e+000$

Contour of SZZ

Plane: on

Magfac $=1.000 e+000$

Gradient calculation

=

$-1.9682 e+007$ to $-1.8000 e+007$

$-1.8000 e+007$ to $-1.5000 e+007$

$-1.5000 e+007$ to $-1.2000 e+007$

$-1.2000 e+007$ to $-9.0000 e+006$

$-9.0000 e+006$ to $-6.0000 e+006$

$-6.0000 e+006$ to $-3.0000 e+006$

$-3.0000 e+006$ to $0.0000 e+000$

Interval $=3.0 e+006$

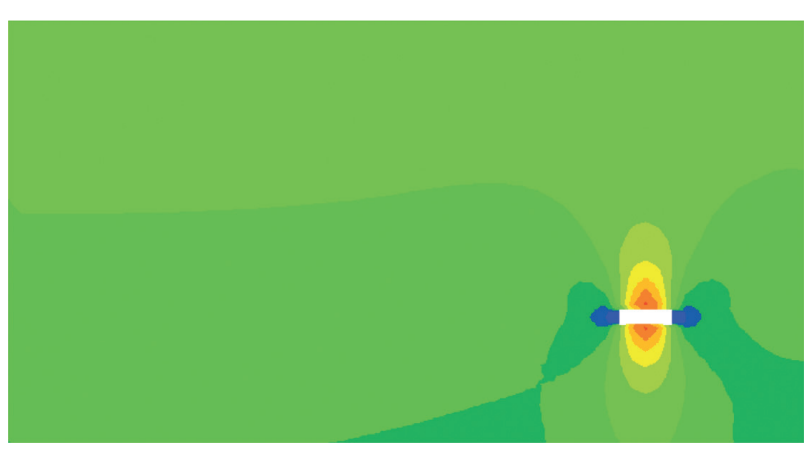

(a)

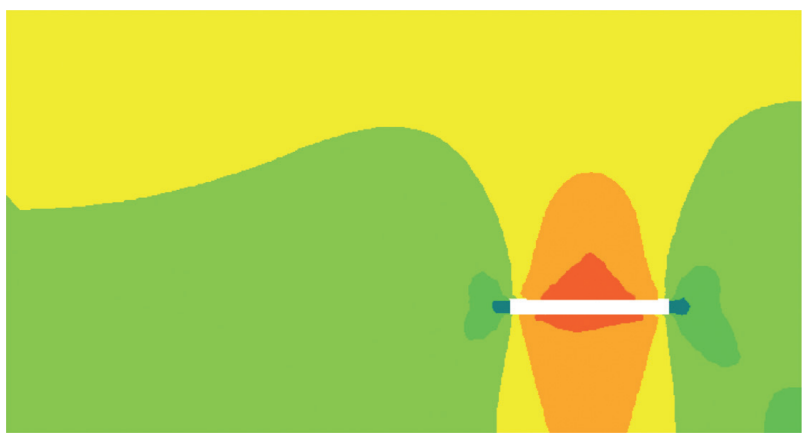

(b)

Figure 10: Continued. 


\begin{tabular}{|c|c|}
\hline Center: & Rotation: \\
\hline$X: 1.500 e+002$ & $X: 0.000$ \\
\hline$Y: 1.500 e+002$ & $Y: 0.000$ \\
\hline$Z: 7.999 e+001$ & $Z: 90.000$ \\
\hline $\begin{array}{l}\text { Dist: } 9.795 e+002 \\
\text { Increments: } \\
\text { Move: } 3.897 e+00 \\
\text { Rot.: } 10.000\end{array}$ & $\begin{array}{l}\text { Mag.: } 1.95 \\
\text { Ang.: } 22.500\end{array}$ \\
\hline Plane origin: & Plane normal: \\
\hline$X: 1.500 e+002$ & $X: 1.000 e+000$ \\
\hline$Y: 0.000 e+000$ & $Y: 0.000 e+000$ \\
\hline $\begin{array}{l}Z: 0.000 e+000 \\
\text { Contour of SZZ } \\
\text { Plane: on } \\
\text { Magfac }=1.000 \\
\text { Gradient calcu } \\
-2.2452 e+007\end{array}$ & $\begin{array}{l}e+000 \\
\text { ation } \\
\text { to }-2.1000 e+007\end{array}$ \\
\hline$-2.1000 e+007$ & to $-1.8000 e+007$ \\
\hline$-1.8000 e+007$ & to $-1.5000 e+007$ \\
\hline$-1.5000 e+007$ & to $-1.2000 e+007$ \\
\hline$-1.2000 e+007$ & to $-9.0000 e+006$ \\
\hline$-9.0000 e+006$ & to $-6.0000 e+006$ \\
\hline$-6.0000 e+006$ & to $-3.0000 e+006$ \\
\hline$-3.0000 e+006$ & to $0.0000 e+000$ \\
\hline
\end{tabular}

Center:

$X: 1.500 e+002$

$Y: 1.500 e+002$

$Z: 7.999 e+001$

Dist: $9.795 e+002$

Increments:

Move: $3.897 e+001$

Rot.: 10.000

Plane origin:

Plane normal:

$X: 1.500 e+002$

$X: 1.000 e+000$

$Y: 0.000 e+000$

$Z: 0.000 e+000$

Contour of SZZ

Plane: on

Magfac $=1.000 e+000$

Gradient calculation

$-$

$-2.3452 e+007$ to $-2.1000 e+007$

$-2.1000 e+007$ to $-1.8000 e+007$

$-1.8000 e+007$ to $-1.5000 e+007$

$-1.5000 e+007$ to $-1.2000 e+007$

$-1.2000 e+007$ to $-9.0000 e+006$

$-9.0000 e+006$ to $-6.0000 e+006$

$-6.0000 e+006$ to $-3.0000 e+006$

$-3.0000 e+006$ to $0.0000 e+000$

Interval $=3.0 e+006$

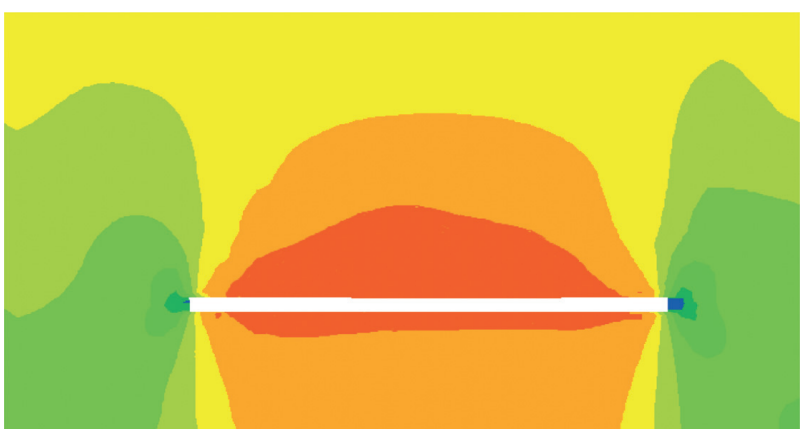

(e)

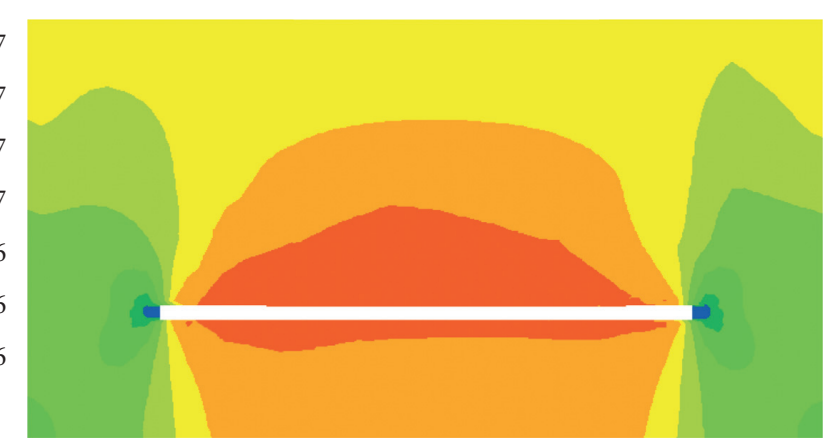

(f)

Figure 10: Vertical stress of the section along the trending direction (different advance length). (a) Working face advancing $20 \mathrm{~m}$. (b) Working face advancing $60 \mathrm{~m}$. (c) Working face advancing $100 \mathrm{~m}$. (d) Working face advancing $140 \mathrm{~m}$. (e) Working face advancing $180 \mathrm{~m}$. (f) Working face advancing $200 \mathrm{~m}$. 


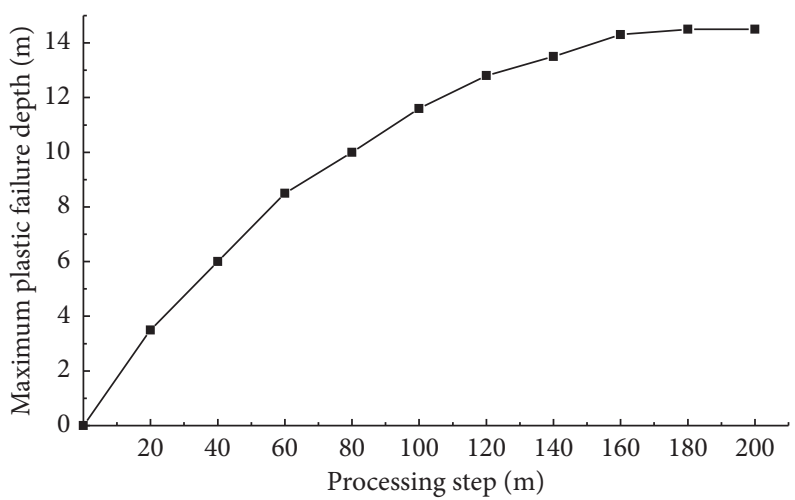

Figure 11: Maximum depth of floor plastic failure in different steps.

working face, namely, near the two parallel grooves, the lower layer of coal is prone to shear failure. In this area, the floor failure depth is the largest, and the displacement of coal and rock mass is the largest. Therefore, the lower layer of coal movement for $0 \mathrm{~m}$ contour is approximately "inverted saddle" shape.

To sum up, in the case of relatively small displacement under the floor, no large plastic damage will be caused, and the borehole will not be damaged.

\section{Reasonable Range Analysis of Kilometer Borehole}

5.1. Depth Range of Borehole along Floor. According to the theoretical calculation and numerical simulation results, the maximum floor failure depth of 205 working face is determined to be about $13 \mathrm{~m}$. Comprehensive analysis of the simulation results shows that the coal and rock mass is in the fully pressure-relief area when the vertical depth of the floor is $0 \sim 3 \mathrm{~m}$ and is completely in the plastic plane failure. The displacement of coal and rock mass can reach more than $70 \mathrm{~mm}$, and the damage degree is serious, so the stability and integrity of kilometer drilling are greatly threatened. In the range of $3 \sim 6 \mathrm{~m}$, the coal body is still in the fully pressure-relief area, and the plastic failure is mainly plane. The moving distance to the goaf can reach more than $40 \mathrm{~mm}$. The vertical and cross cracks are fully developed, which provides a channel for the gas flow below. At $6 \mathrm{~m}$ below the floor, only local plastic failure occurs in the coal body. The degree of pressure relief is reduced, and the displacement is about $20 \mathrm{~mm}$. The failure of the coal body is relatively reduced, and the cracks are fully developed. The arrangement of long boreholes with kilometer strike in this area can not only maintain integrity for a long time but also effectively prevent the pressure-relief gas from entering the goaf through vertical cracks. At 6 9 m, the coal body is mainly fractured. The borehole can maintain the original shape and can extract the pressure-relief gas from the lower layer for a long time, which provides a reliable guarantee for the lower layer mining. At $6 \sim 9 \mathrm{~m}$, the failure of coal body is dominated by tensile fracture, and the borehole can maintain the original shape, which can be used to extract the pressure-relief gas in the lower layer for a long time, and provide reliable guarantee for the lower layer mining. Under $12 \mathrm{~m}$, there is only plastic failure near the groove in the coal body, and the displacement is less than $10 \mathrm{~mm}$, so the borehole can be arranged at this position. However, because the lower layer is only $13 \mathrm{~m}$, the borehole will not be fully utilized and the benefit will not be maximized. At the same time, the pressure-relief gas of the coal body in the region flows upward, and the pressurerelief gas is cut off by the upper part of the drilling group under the action of pressure difference so that it cannot cross to the goaf.

In summary, when the borehole is arranged in the coal seam with relatively small plastic failure and floor displacement, it is about 6 9 $\mathrm{m}$ below the vertical depth of the floor, which can ensure that the possibility of borehole collapse is low. Therefore, the borehole can achieve the purpose of continuous drainage in the process of advancing the working face.

5.2. Tendency Range of Borehole along Working Face. Due to the sufficient roof caving in the middle of the goaf, the dense filling, and the support of the left coal pillars on both sides, the coal on both sides can be in a noncompaction state for a long time compared with the middle compaction area. Therefore, along the inclination of the working face, within a certain width on both sides, the gas concentration is high, the degree of pressure relief is sufficient, and the floor kilometer drilling can maximize its role.

At $150 \mathrm{~m}$ of the central line of the working face, within $60 \mathrm{~m}$ from the coal wall of the working face to the goaf, the vertical displacement of the coal and rock with the floor droop depth of $1 \mathrm{~m}, 3 \mathrm{~m}, 6 \mathrm{~m}, 9 \mathrm{~m}$, and $13 \mathrm{~m}$ was taken, shown in Figure 14. At the coal wall of the working face, the coal and rock mass of the floor moves downward. From the coal wall to the goaf $20 \mathrm{~m}$, the displacement has been increased, and the inflection point appears at $20 \mathrm{~m}$. Due to the stress recovery and roof caving, the displacement begins to decrease. At $1 \mathrm{~m}$ and $3 \mathrm{~m}$, the floor displacement variation reaches $0.18 \mathrm{~m}$ and $0.14 \mathrm{~m}$, and the displacement variation is relatively intense, which is very easy to cause coal damage. With the increase of the vertical depth, the displacement difference decreases and the displacement values decrease accordingly. The displacement difference at $6 \mathrm{~m}, 9 \mathrm{~m}$, and 


\begin{tabular}{|c|c|}
\hline Center: & Rotation: \\
\hline$X: 1.500 e+002$ & $X: 90.000$ \\
\hline$Y: 1.500 e+002$ & $Y: 0.000$ \\
\hline$Z: 7.993 e+001$ & $Z: 0.000$ \\
\hline Dist: $1.051 e+003$ & Mag.: 1.25 \\
\hline $\begin{array}{l}\text { Increments: } \\
\text { Move: } 3.897 e+001 \\
\text { Rot.: } 10.000\end{array}$ & Ang.: 22.500 \\
\hline Plane origin: & Plane normal: \\
\hline$X: 0.000 e+000$ & $X: 0.000 e+000$ \\
\hline$Y: 0.000 e+000$ & $Y: 0.000 e+000$ \\
\hline$Z: 4.400 e+001$ & $Z: 1.000 e+000$ \\
\hline ock state & \\
\hline
\end{tabular}

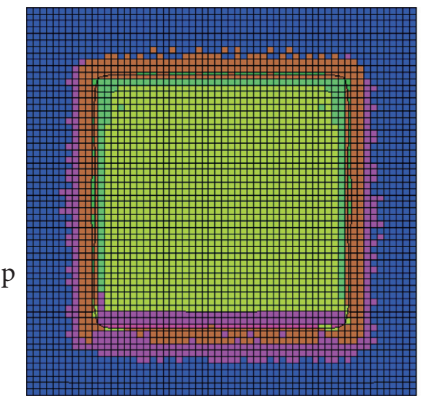

(a)
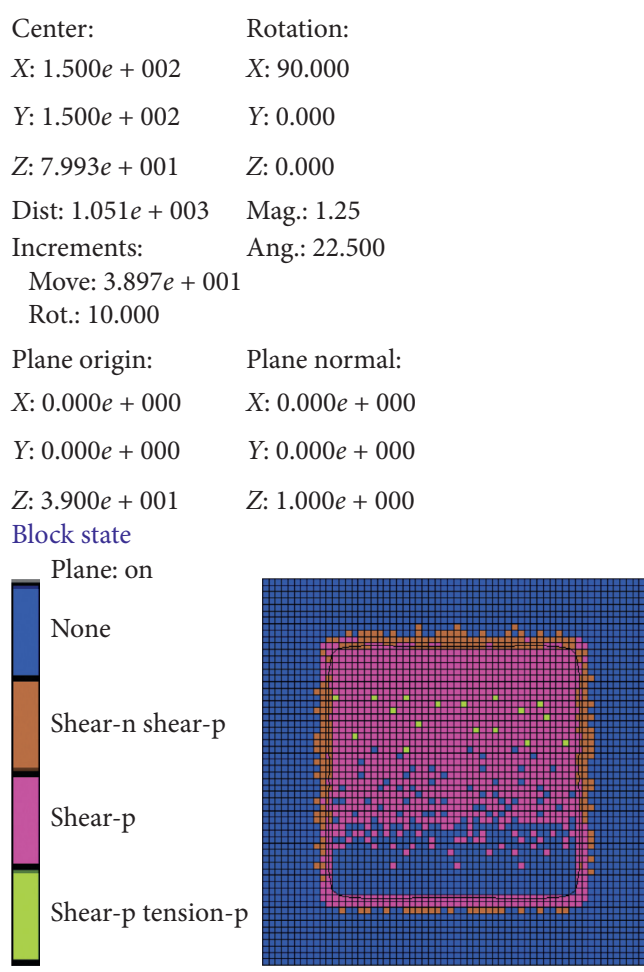

(c)
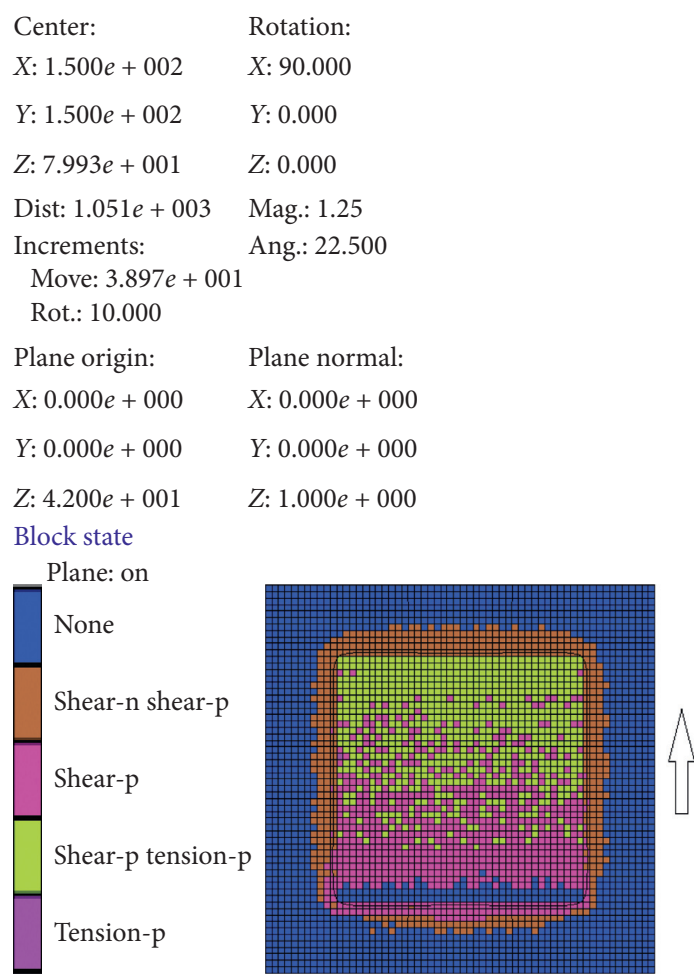

(b)

Center: Rotation:

$X: 1.500 e+002 \quad X: 90.000$

$Y: 1.500 e+002 \quad Y: 0.000$

$Z: 7.993 e+001 \quad Z: 0.000$

Dist: $1.051 e+003 \quad$ Mag.: 1.25

Increments: Ang.: 22.500

Move: $3.897 e+001$

Rot.: 10.000

Plane origin: Plane normal:

$X: 0.000 e+000 \quad X: 0.000 e+000$

$Y: 0.000 e+000 \quad Y: 0.000 e+000$

$Z: 3.600 e+001 \quad Z: 1.000 e+000$

Block state

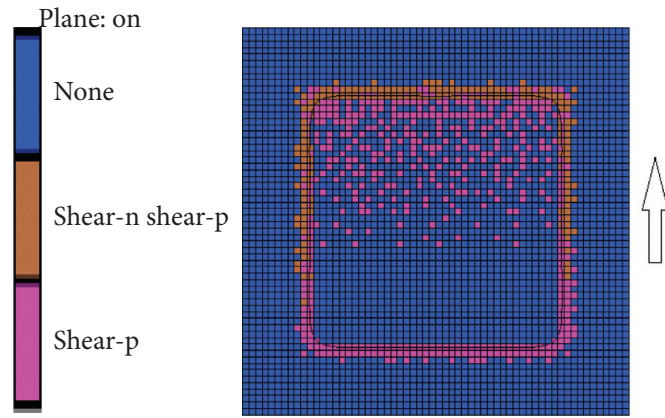

(d)

Figure 12: Continued. 

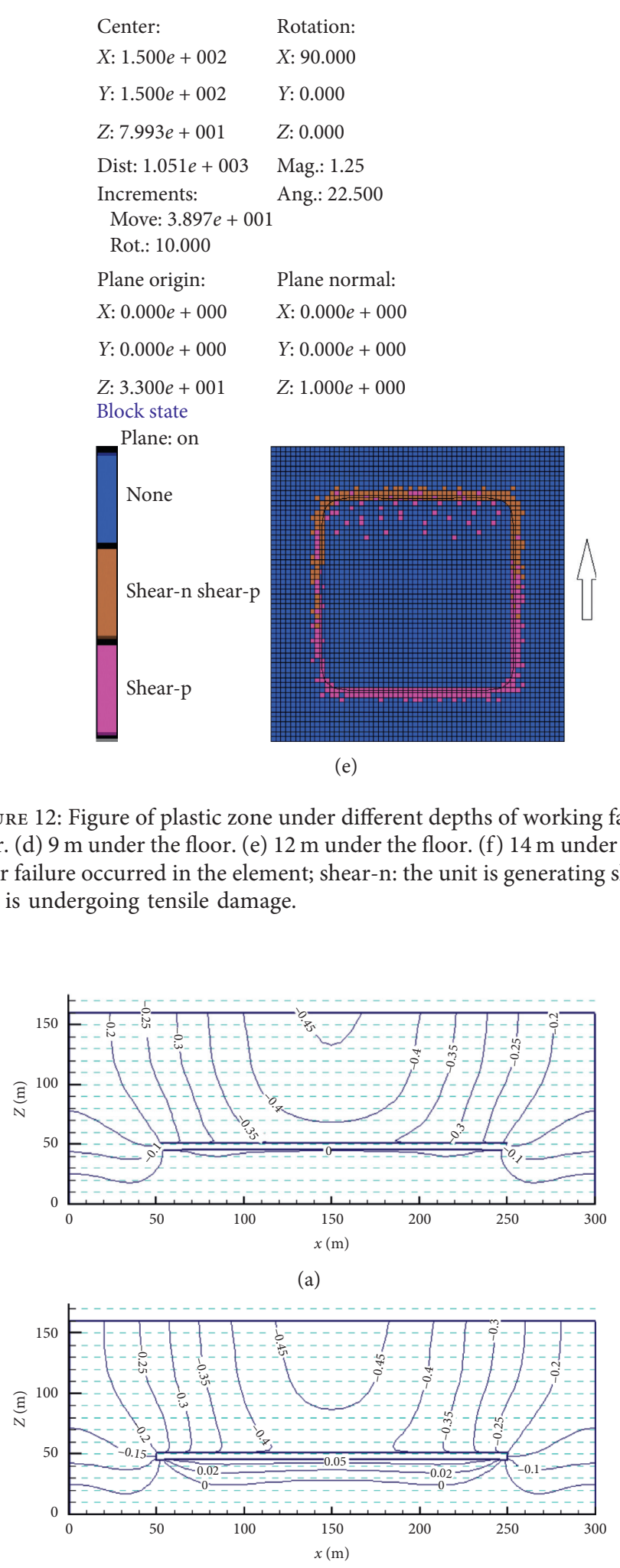
unit is undergoing tensile damage. (a)

(c)
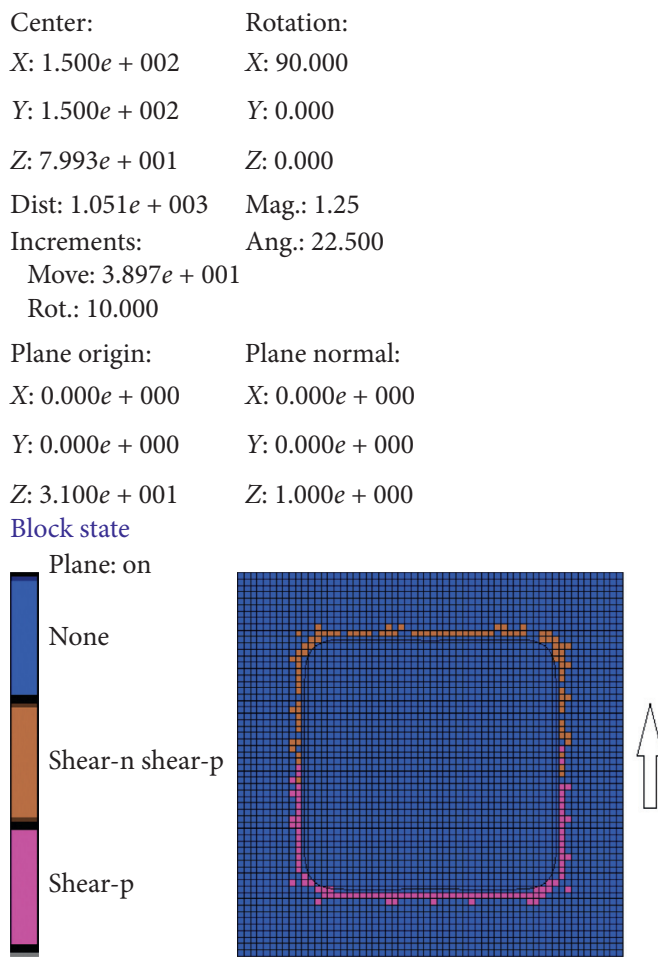

(f)

Figure 12: Figure of plastic zone under different depths of working face. (a) $1 \mathrm{~m}$ under the floor. (b) $3 \mathrm{~m}$ under the floor. (c) $6 \mathrm{~m}$ under the floor. (d) $9 \mathrm{~m}$ under the floor. (e) $12 \mathrm{~m}$ under the floor. (f) $14 \mathrm{~m}$ under the floor. Legend: none: no shear failure occurred in the unit; shear-p: shear failure occurred in the element; shear-n: the unit is generating shear failure; tension-p: units were damaged by tension; tension-n: the

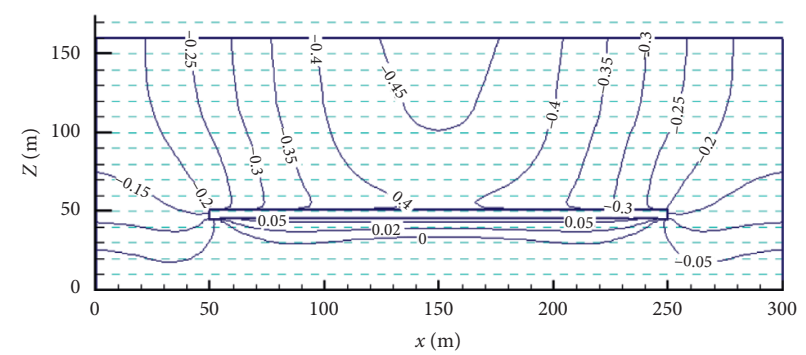

(b)

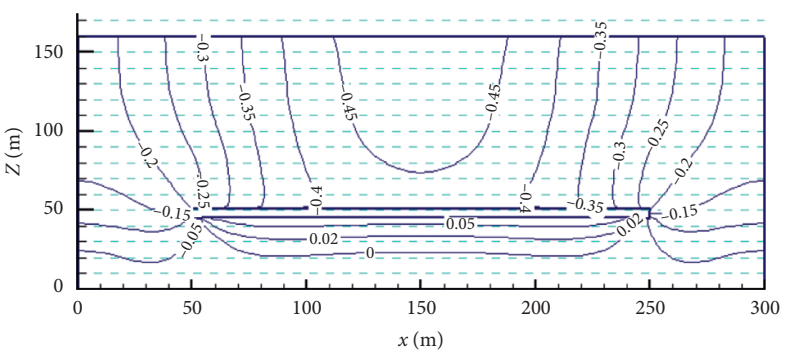

(d)

Figure 13: Contour map of displacement of the section along the tendency direction. (a) $3 \mathrm{~m}$ from coal seam of working face. (b) $5 \mathrm{~m}$ from coal seam of working face. (c) $7 \mathrm{~m}$ from coal seam of working face. (d) $9 \mathrm{~m}$ from coal seam of working face. 


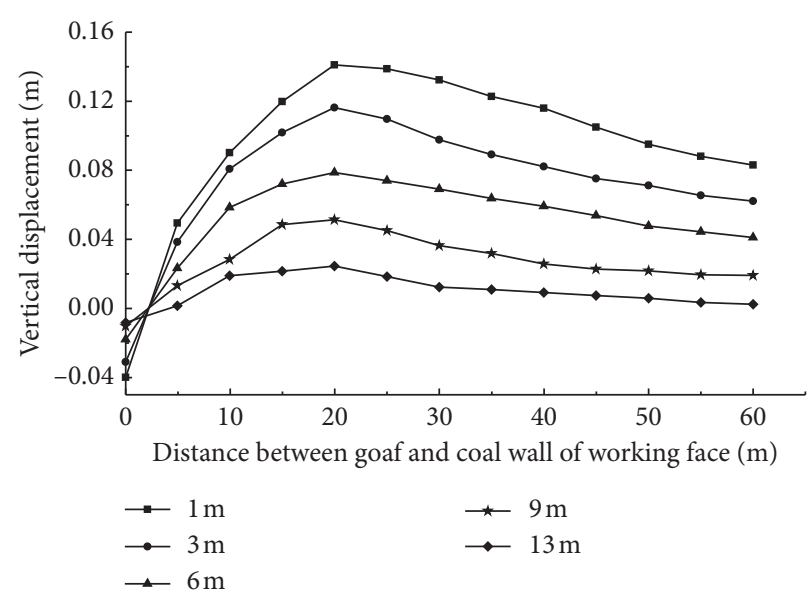

Figure 14: Variation of vertical movement with different distance in the floor (centerline of working face).

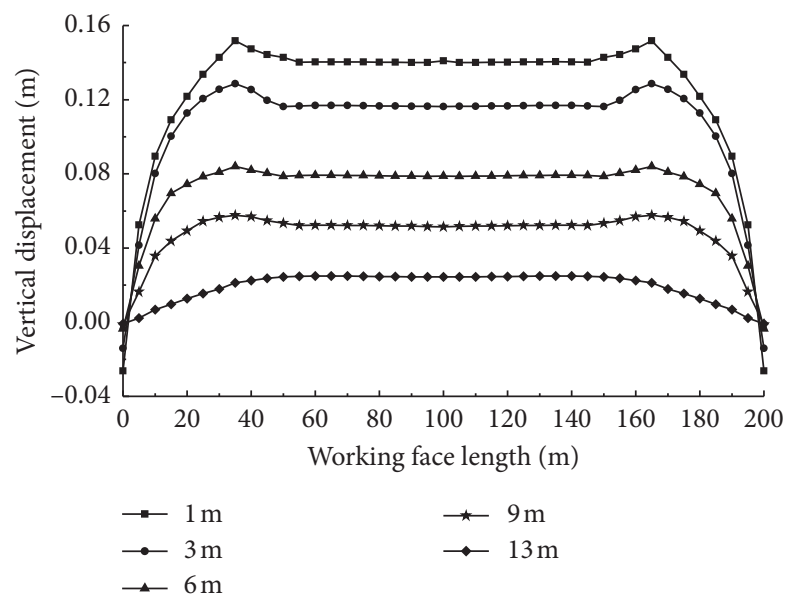

FIGURE 15: Variation of vertical movement with different distance in the floor (coal wall to $20 \mathrm{~m}$ in goaf).

$13 \mathrm{~m}$ is $0.09 \mathrm{~m}, 0.06 \mathrm{~m}$, and $0.03 \mathrm{~m}$, respectively, which are less than the diameter of the kilometer borehole.

The displacement of the floor at $20 \mathrm{~m}$ away from the goaf of the working face reaches its peak, so the displacement at different vertical depths is taken every $5 \mathrm{~m}$ along the inclination of the working face, as shown in Figure 15.

As the vertical depth increases, the amount of displacement decreases, and the amount of displacement reaches the peak at the staggered $35 \mathrm{~m}$ in the two troughs. At the centerline of the working face, due to the caving of the roof, the displacement is minimal, and the degree of pressure relief and permeability is small relative to the periphery. The displacements at $1 \mathrm{~m}$ and $3 \mathrm{~m}$ below the vertical depth of the floor vary greatly, and the saddle-like protrusions are very obvious. The displacement difference within $20 \mathrm{~m}$ is large, which is likely to cause fractured destruction of the coal body. Therefore, borehole layout in this area is easy to collapse. Below $6 \mathrm{~m}$, the saddle-like protrusions tend to relax obviously, and from $15 \mathrm{~m}$ to $45 \mathrm{~m}$ in the two troughs, the displacement does not increase or decrease sharply in a local range. At the same time, this part of the area is located in the " $O$ " circle, the roof falling behind is not easy to compaction, the floor displacement is large, there is no plastic damage, the degree of pressure relief is sufficient, and the permeability of the lower layer is good. Based on the above, the optimal effect of gas drainage can be achieved by arranging more kilometers of boreholes in the range.

\section{Conclusions}

In this paper, the 205 working face of Tingnan Coal Mine is taken as the background. For the purpose of controlling the stratified pressure-relief gas, the theoretical analysis of the failure depth and type of the floor is carried out by combining the theoretical calculation and numerical simulation. Through the verification of field test, the reasonable range of kilometer drilling is obtained. The specific conclusions are as follows: 
(1) Through theoretical calculation, the maximum plastic failure depth of the floor of 205 working face is $12.89 \mathrm{~m}$, and the maximum failure depth is $6.85 \mathrm{~m}$ away from the coal wall of the working face. The lower layer coal is all in the pressure-relief range, resulting in that goaf gas mainly comes from the lower layer pressure-relief coal body. In the stratified mining of extrathick coal seam with high gas, under the effect of "pressure relief and flow increase," a large number of pressure-relief gases gushed into the working face, which became the main source of gas emission in the working face.

(2) The numerical simulation of the upper slicing mining of 4\# coal seam in 205 working face of Tingnan Coal Mine is carried out. Through the vertical stress analysis of different advancing distances of the working face, the plastic failure degree of each section under different vertical depths of the floor is analyzed. The results show that when advancing to $200 \mathrm{~m}$, the $13 \mathrm{~m}$ coal body in the lower slicing is all in the pressure-relief range.

(3) Numerical simulation is carried out to determine the reasonable range of 205 working face lower layer kilometer drilling. Based on the analysis of the stress distribution, plastic deformation, and displacement of floor, the range and law of the pressure-relief area under the bottom plate are obtained [37].

\section{Data Availability}

The data used to support the findings of this study are available from the corresponding author upon request.

\section{Conflicts of Interest}

All the authors declare that they have no conflicts of interest.

\section{Acknowledgments}

Special thanks are due to Yanwen Zhang for her contribution to this paper in some data analysis work. This research was funded by the Innovative Training Program for College Students (C202012145, C202012135, and C202112003).

\section{References}

[1] F. Du, K. Wang, G. Wang, Y. Huang, and L. Yi, "The mechanism of damage in gas-bearing coal-rock combination bodies and gas seepage in coals," Energy Sources, Part A: Recovery, Utilization, and Environmental Effects, vol. 43, no. 10, pp. 1181-1201, 2021.

[2] A. Liu, S. Liu, P. Liu, and K. Wang, "Water sorption on coal: effects of oxygen containing function groups and pore structure," International Journal of Coal Science and Technology, vol. 2, pp. 1-20, 2021.

[3] A. Liu, S. Liu, P. Liu, and S. Harpalani, "The role of sorptioninduced coal matrix shrinkage on permeability and stress evolutions under replicated in situ condition for CBM reservoirs," Fuel, vol. 294, Article ID 120530, 2021.
[4] H. Wang, B. Tan, Z. Shao, Y. Guo, Z. Zhang, and C. Xu, "Influence of different content of FeS2 on spontaneous combustion characteristics of coal," Fuel, vol. 288, Article ID 119582, 2021.

[5] H. Wang, X. Fang, F. Du et al., "Three-dimensional distribution and oxidation degree analysis of coal gangue dump fire area: a case study," The Science of the Total Environment, vol. 772, Article ID 145606, 2021.

[6] F. Du, K. Wang, X. Zhang, C. Xin, L. Shu, and G. Wang, "Experimental study of coal-gas outburst: insights from coalrock structure, gas pressure and adsorptivity," Natural Resources Research, vol. 29, no. 4, pp. 2481-2493, 2020.

[7] D. Guo, P. Lv, J. Zhao, and C. Zhang, "Research progress on permeability improvement mechanisms and technologies of coalbed deep-hole cumulative blasting," International Journal of Coal Science and Technology, vol. 7, no. 2, pp. 329-336, 2020.

[8] X. Li, S. Chen, E. Wang, and Z. Li, "Rockburst mechanism in coal rock with structural surface and the microseismic (MS) and electromagnetic radiation (EMR) response," Engineering Failure Analysis, vol. 124, no. 6, Article ID 105396, 2021.

[9] K. Wang and F. Du, "Coal-gas compound dynamic disasters in China: a review," Process Safety and Environmental Protection, vol. 133, pp. 1-17, 2020.

[10] Q. Zou, B. Lin, C. Zheng et al., "Novel integrated techniques of drilling-slotting-separation-sealing for enhanced coal bed methane recovery in underground coal mines," Journal of Natural Gas Science and Engineering, vol. 26, pp. 960-973, 2015.

[11] D. Fu, G. Xu, L. Ma et al., "Gas generation from coal: taking jurassic coal in the Minhe basin as an example," International Journal of Coal Science \& Technology, vol. 7, no. 3, pp. 611-622, 2020.

[12] S. V. Valiulin, A. A. Onischuk, A. M. Baklanov et al., "Effect of coal mine organic aerosol on the methane/air lower explosive limit," International Journal of Coal Science \& Technology, vol. 7, no. 4, pp. 778-786, 2020.

[13] Q. X. Yu, Y. P. Cheng, C. L. Jiang, and S. N. Zhou, "Principles and applications of exploitation of coal and pressure relief gas in thick and high-gas seams," Journal of China University of Mining and Technology, vol. 33, no. 2, pp. 3-7, 2004.

[14] X. R. Meng, C. H. Xu, Z. N. Gao, and X. Q. Wang, "Stress distribution and damage mechanism of mining floor," Journal of China Coal Society, vol. 35, no. 11, pp. 1832-1836, 2010.

[15] P. P. Wang, Y. X. Zhao, Y. D. Jiang et al., "Characteristics and control technology of water inrush from deep coal seam floor above confined aquifer in Xingdong coal mine," Journal of China Coal Society, vol. 45, no. 7, pp. 2444-2454, 2020.

[16] Y. Zhang, "Mechanism of water inrush of a deep mining floor based on coupled mining pressure and confined pressure," Mine Water and the Environment, vol. 40, pp. 366-377, 2021.

[17] G. X. Xie and J. C. Chang, "Study on overcutting-bolting \& grouting-backfilling concrete to control the floor heave of deep mine roadway," Journal of China Coal Society, vol. 35, no. 8, pp. 1242-1246, 2010.

[18] X. F. Guo, Y. G. Li, G. D. Zhou, Z. J. He et al., "Stability analysis and reasonable layout of floor drainage roadway above confined water and under mining influence," Geofluids, vol. 2021, Article ID 5578717, 11 pages, 2021.

[19] A. Liu, S. Tu, F. Wang, Y. Yuan, C. Zhang, and Y. Zhang, "Numerical simulation of pressure relief rule of upper and lower protected coal-seam in thin-protective-seam mining," Disaster Advances, vol. 6, pp. 16-25, 2013. 
[20] H. Z. Zhu, P. Liu, and Z. Y. Tong, "Numerical simulation research and application on protected layer pressure relief affection under different coal pillar width," Procedia Engineering, vol. 84, pp. 818-825, 2014.

[21] W. Zhao, K. Wang, R. Zhang, H. Dong, Z. Lou, and F. An, "Influence of combination forms of intact sub-layer and tectonically deformed sub-layer of coal on the gas drainage performance of boreholes: a numerical study," International Journal of Coal Science \& Technology, vol. 7, no. 3, pp. 571-580, 2020.

[22] Y. P. Cheng, D. Y. Zhou, Q. X. Yu, H. X. Zhou et al., "Research on extraction and emission laws of gas for pressure-relief in protecting coal seams," Journal of Mining \& Safety Engineering, vol. 23, no. 1, pp. 12-18, 2006.

[23] Q. Zou, H. Liu, Z. Cheng, T. Zhang, and B. Lin, "Effect of slot inclination angle and borehole-slot ratio on mechanical property of pre-cracked coal: implications for ECBM recovery using hydraulic slotting," Natural Resources Research, vol. 29, no. 3, pp. 1705-1729, 2020.

[24] Q. Zou, H. Liu, Y. Zhang, Q. Li, J. Fu, and Q. Hu, "Rationality evaluation of production deployment of outburst-prone coal mines: a case study of Nantong coal mine in Chongqing, China," Safety Science, vol. 122, Article ID 104515, 2020.

[25] J. Lu and K. J. Xiong, "Application of horizontal $1000 \mathrm{~m}$ directional drilling rig to mine gas drainage," Coal Science and Technology, vol. 39, no. 12, pp. 92-95, 2011.

[26] X. M. Zhu, T. M. Jiang, and H. D. Miao, "Local gas drainage trial in Sihe mine," Coal Science and Technology, vol. 2, pp. 33-35, 2003.

[27] X. Q. Fang, Y. Q. Geng, and M. Wang, "Kilometer directional drilling: simultaneous extraction of coal and gas from a high gas coal seam," Journal of China University of Mining and Technology, vol. 41, no. 6, pp. 885-892, 2012.

[28] T. Q. Xia, H. Y. Ren, H. Li, and C. K. Du, "A method to remove gas hazard around underground thrust faults kilometer directional feathery drilling," Thermal Science, vol. 23, no. 6, pp. 3767-3774, 2019.

[29] K. Wang, F. Du, and G. Wang, "Investigation of gas pressure and temperature effects on the permeability and steady-state time of Chinese anthracite coal: an experimental study," Journal of Natural Gas Science and Engineering, vol. 40, pp. 179-188, 2017.

[30] H. Wang, X. Yang, F. Du et al., "Calculation of the diffusion coefficient of gas diffusion in coal: the comparison of numerical model and traditional analytical model," Journal of Petroleum Science and Engineering, vol. 205, Article ID 108931, 2021.

[31] X. Wu, Y. Peng, J. Xu, Q. Yan, W. Nie, and T. Zhang, "Experimental study on evolution law for particle breakage during coal and gas outburst," International Journal of Coal Science \& Technology, vol. 7, no. 1, pp. 97-106, 2020.

[32] F. Du and K. Wang, "Unstable failure of gas-bearing coal-rock combination bodies: insights from physical experiments and numerical simulations," Process Safety and Environmental Protection, vol. 129, pp. 264-279, 2019.

[33] Y. B. Guan, H. M. Li, and J. C. Lu, "Research on No. 9 coal seam floor's fracture regularity in Xiandewang coal mine," Journal of China Coal Society, vol. 28, no. 2, pp. 121-125, 2003.

[34] F. K. Xiao, L. Q. Duan, and Z. H. Ge, "Laws of floor breaking in coal mining face and gas extraction application," Journal of China Coal Society, vol. 35, no. 3, pp. 417-419, 2010.

[35] C. Xin, F. Du, K. Wang, C. Xu, S. Huang, and J. Shen, "Damage evolution analysis and gas-solid coupling model for coal containing gas," Geomechanics and Geophysics for GeoEnergy and Geo-Resources, vol. 7, no. 1, p. 7, 2021.

[36] Q. X. Qi, W. B. Ji, J. H. Yuan, Z. H. Cheng et al., "Theory, insitu observation on the floor connected crack field and its effects on methane extraction," Journal of China Coal Society, vol. 39, no. 8, pp. 1552-1558, 2014.

[37] X. Y. Yu, Q. Wang, B. C. Zhao, and L. F. Wang, "Analysis on mine strata pressure law of high cutting coal mining face and suitability of powered support," Coal Technology, vol. 33, no. 5, pp. 154-156, 2014. 